\title{
How many fish? Comparison of two underwater visual sampling methods for monitoring fish communities
}

\author{
Zoi Thanopoulou ${ }^{\text {Corresp., }}{ }^{1,2}$, Maria Sini ${ }^{3}$, Konstantinos Vatikiotis ${ }^{3}$, Christos Katsoupis ${ }^{3}$, Panayiotis G \\ Dimitrakopoulos $^{2}$, Stelios Katsanevakis ${ }^{3}$ \\ 1 Department of Biology, University of Miami, MIAMI, FLORIDA, United States \\ 2 Department of the Environment, Aegean University, Mytilene, Greece \\ 3 Department of Marine Sciences, Aegean University, Mytilene, Greece \\ Corresponding Author: Zoi Thanopoulou \\ Email address: zxt89@miami.edu
}

Background. Underwater visual surveys for monitoring fish communities are preferred over fishing surveys in certain habitats, such as rocky or coral reefs and seagrass beds and are the standard monitoring tool in many cases, especially in protected areas. However, despite their wide application there are potential biases, mainly due to imperfect detectability and the behavioral responses of fish to the observers.

Methods. The performance of two methods of underwater visual surveys were compared to test whether they give similar results in terms of fish population density, occupancy, species richness and community composition. Distance sampling (line transects) and plot sampling (strip transects) were conducted at 31 rocky-reef sites in the Aegean Sea (Greece) using SCUBA diving.

Results. Line transects generated significantly higher values of occupancy, species richness, and total fish density, compared to strip transects. For most species, density estimates differed significantly between the two sampling methods. For secretive species and species avoiding the observers, the line transect method yielded higher estimates, as it accounted for imperfect detectability and utilized a larger survey area compared to the strip transect method. On the other hand, large-scale spatial patterns of species composition were similar for both methods.

Discussion. Overall, both methods presented a number of advantages and limitations, which should be considered in survey design. Line transects appear to be more suitable for surveying secretive species, while strip transects should be preferred at high fish densities and for species of high mobility. 
1 How many fish? Comparison of two underwater visual

2 sampling methods for monitoring fish communities

3 Zoi Thanopoulou ${ }^{* 1,2}$, Maria $\operatorname{Sini}^{3}$, Konstantinos Vatikiotis ${ }^{3}$, Christos Katsoupis ${ }^{3}$, Panayiotis G.

4 Dimitrakopoulos ${ }^{2}$, Stelios Katsanevakis ${ }^{3}$

$5{ }^{1}$ Department of Biology, University of Miami, Miami, FL 33146, United States

$6{ }^{2}$ Department of the Environment, University of the Aegean, Mytilene 81100, Greece

$7{ }^{3}$ Department of Marine Sciences, University of the Aegean, Mytilene 81100, Greece

9

10 Corresponding Author:

11 Zoi Thanopoulou ${ }^{1}$

12 Cox Science Building, 1301 Memorial Drive, Coral Gables, FL 33146, USA

13 Email address: zoi.than90@gmail.com 
15 Abstract

16 Background. Underwater visual surveys for monitoring fish communities are preferred over

17 fishing surveys in certain habitats, such as rocky or coral reefs and seagrass beds and are the

18 standard monitoring tool in many cases, especially in protected areas. However, despite their

19 wide application there are potential biases, mainly due to imperfect detectability and the

20 behavioral responses of fish to the observers.

21 Methods. The performance of two methods of underwater visual surveys were compared to test

22 whether they give similar results in terms of fish population density, occupancy, species richness

23 and community composition. Distance sampling (line transects) and plot sampling (strip

24 transects) were conducted at 31 rocky-reef sites in the Aegean Sea (Greece) using SCUBA

25 diving.

26 Results. Line transects generated significantly higher values of occupancy, species richness, and

27 total fish density, compared to strip transects. For most species, density estimates differed

28 significantly between the two sampling methods. For secretive species and species avoiding the observers, the line transect method yielded higher estimates, as it accounted for imperfect detectability and utilized a larger survey area compared to the strip transect method. On the other hand, large-scale spatial patterns of species composition were similar for both methods.

32 Discussion. Overall, both methods presented a number of advantages and limitations, which

33 should be considered in survey design. Line transects appear to be more suitable for surveying secretive species, while strip transects should be preferred at high fish densities and for species of high mobility. 
37

38

39

40

41

42

\section{Introduction}

In recent decades, several sampling approaches have been developed for the assessment of fish communities in different marine habitat types. Selecting the most suitable sampling method is a crucial step during the survey design process. This decision is usually dictated by the overall research objectives, the level of accuracy needed to address scientific questions, the time and resource availability to carry out the survey, as well as the physical, ecological and behavioral characteristics of the fish and habitats under investigation (Lessios 1996; Rotherham et al. 2007). Non-destructive approaches such as Underwater Visual Survey methods (UVS; Hill and Wilkinson 2004; Andaloro et al. 2011, 2013) are preferred when assessing protected or endangered species or when sampling in vulnerable habitat types such as coral reefs and seagrass meadows.

UVS methods for the assessment of fish include five main quantitative or semi-quantitative methods, which can be carried out either through SCUBA or free diving or through the examination of video and photographic records. These methods include plot sampling (strip transects and point counts), distance sampling (line transects and point transects), fixed-time transects, occupancy estimation based on repetitive sampling, and rapid visual techniques (described in detail in Katsanevakis et al. 2012). In this study, the first two methods (specifically, strip transects and line transects) were further analyzed and compared. These two methods were selected as they are the only UVS techniques that provide absolute abundance estimations, while the other three are less informative, as they provide estimates of either indices of abundance or probability of presence. 
59 In shallow water reef fish assemblages, plot sampling, and especially the strip transect method, is

60 the most widely used UVS technique ( Samoilys and Carlos 2000; Caldwell et al. 2016;

61 Friedlander et al. 2018). Strip transects are a simple, low-cost technique that can be performed

62 through SCUBA diving or snorkeling, depending on water visibility and depth, with minimum equipment requirements (Holmes et al. 2013). During strip transects, observations of target fish are made within a predetermined surface area (Côté and Perrow 2006). Mapstone and Ayling (1993) proposed that mid-sized strips, i.e. 50 or $75 \mathrm{~m}$ length and 5 or $10 \mathrm{~m}$ width, are suitable to obtain a representative sample of the fish community. The optimal swimming speed of the observer is usually accepted to be a compromise between a rapid constant pace (necessary to avoid implications due to fish movement) and search efficiency (Samoilys and Carlos 2000).

A crucial assumption in strip transect sampling is that detectability within the investigated area is perfect. Yet again, when assessing fish populations, there are several reasons that may lead to imperfect detectability, and subsequently, result in an underestimation of species composition and population density (Monk 2014). Several studies have shown that detectability varies considerably across fish species and is mostly affected by body size, schooling behavior, shyness and secretive coloration or behavior (MacNeil et al. 2008b; Bozec et al. 2011). Environmental factors such as habitat complexity (Edgar and Barrett 1999) and water visibility (MacNeil et al. 2008a, b) also influence detectability. Alongside the various morphological and ecological characteristics of different species and habitats, several methodological factors, such as the selection of strip width, also affect the level of detectability (Kulbicki and Sarramégna 1999). Consequently, species richness and abundance may be substantially underestimated in strip transects (Franzreb 1981; Katsanevakis 2009). 
81 In many cases, the problem of imperfect detectability can be addressed through distance

82 sampling, as this method accounts for detection probability (Buckland et al. 2001, 2004). In the

83

84

85

86

87

88

marine environment, line transects are the most commonly used distance sampling technique (Katsanevakis et al. 2012). The sampling process is similar to that of strip transects, but fish observations are not restricted within a pre-defined strip width; instead, the perpendicular distance of each fish observation from the transect line is recorded. These perpendicular distances are then used to account for the detection probability (Buckland et al. 2001). Estimating the detection probability $\left(\mathrm{P}_{\mathrm{a}}\right)$ is the most important task of the analysis related to distance sampling data (Burnham and Anderson 1984; Buckland et al. 2001).

A critical assumption of distance sampling that should be ensured by the survey design and protocols is that detection on or near the line is perfect (Buckland et al. 2001; Thomas et al. 2010). In the case of violation of this assumption, a negative bias in the estimation of abundance is expected. Another important requirement is that all measurements of the distances are precise. Tape lines and laser rangefinders usually offer more precise measurements than rough estimates by eye, which may be affected by the observers' s visual ability (Thresher and Gunn 1986). Moreover, water turbidity may also affect distance estimations, as in clear waters distances are commonly underestimated, while in turbid waters they are overestimated (Kulbicki 1998).

Both methods suffer from many additional sources of bias. They both depend on the observer's ability to identify fish species in situ (Thompson and Mapstone 1997). Fish are assumed to be observed at their original location, before being influenced by the researcher's presence, as important bias in abundance estimation may be caused due to fish movement in response to observer's presence (Fewster et al. 2008). This largely depends on the behavior of different fish species; if individuals are attracted by the researcher the bias will be positive, while in the case of 
104 avoidance, the bias will be negative. Abundance will also be overestimated if the same 105 individuals are recorded more than once due to their movement ahead of the observer. Biases caused by the observer are likely to be restricted when the observer is experienced (Sale and

107

108

109

110

111

112

113

114

115

116

117

118

119

120

121

122

123

124

125

126
Sharp 1983; Thompson and Mapstone 1997), while biases related to the distribution and

behavior of individuals will differ according to the field protocols. The response of fish towards the observer also varies according to the different levels of fishing pressure in the area under study (Bohnsack and Bannerot 1986; Bellwood 1998). Kulbicki (1998) showed that, due to divergent fish behavior, marine protected areas would seem to have higher estimated fish densities than areas with high fishing pressure even for the same real values of density.

Other recent studies have examined and/or compared the performance of various UVS methods (e.g. Bosch et al. 2017; Irigoyen et al. 2018). Bosch et al. (2017) compared the output of three different methods for studying fish assemblages, UVC (strip transects of fixed length and width), Fish Traps, and Baited Cameras. The authors mainly focused on species diversity; they did not assess the performance of the methods to estimate species absolute or relative abundance. Irigoyen et al. (2018) used conventional strip transects of various fixed width and the distance sampling technique in combination with the 'Tracked Roaming Diver' technique (a sampling method that maximizes the length of the transect and thus the area studied). They proposed that the combination of the two latter methods provides a more efficient way for UVS. However, in their study, only six species of the Western Mediterranean Sea were analyzed restraining their analysis and conclusions to only commercially important, medium- to large-sized reef fishes of the specific area. Comparisons between strip and line transects for UVS for fish have been previously conducted but either focused on specific fish families or on single state metrics, most commonly on population density (e.g. Thresher and Gunn 1986; Kulbicki and Sarramégna 1999) 
127 The aim of our study was to quantitatively compare the performance of the strip and line transect

128 methods, for the assessment and monitoring of Mediterranean rocky reef fish in a non-

129 destructive manner. We estimated a number of univariate and multivariate metrics, such as

130 species occupancy, richness, population density, and composition. For practical and logistical

131 reasons, the study focused on a representative pre-selected group of twenty rocky-reef demersal

132 species covering the widest possible range of trophic groups and behaviors and including both 133 commercially important and non-important species.

\section{Methodology}

136

\section{$137 \quad 2.1 \quad$ Study area}

138 The study area comprises the Greek territorial waters of the Aegean Sea. The study was 139 conducted from July to October 2016 and included 31 rocky reef sites (Fig. 1). None of the sites 140 was in a no-take zone; similar general fishing restrictions applied to all sites with a few 141 exceptions of increased restrictions (Petza et al. 2017). At all hut one site (due to lack of

142 appropriate substratum), two stations were surveyed. The two stations of each site were

143 sufficiently distant so that there was a minimum distance of $50 \mathrm{~m}$ between transects of the two stations.

\subsection{Sampling methods \& target species}

147 At every station both strin and line transects on rocky reef habitats were surveyed by SCUBA

148 diving; the two transects did not overlap in space. The exact location of the starting point of each 
149 strip transect was randomly selected at a depth between 5-15 m; the transect followed an

150 approximately constant depth contour. The starting point of the paired line transect was placed Q

$151 \sim 10 \mathrm{~m}$ apart, and the line transect was conducted in the opposite direction. All surveys were

152 conducted between 10 am and 4 pm, and in every case underwater visibility was at least $20 \mathrm{~m}$.

153 The same set of four observers conducted all surveys. All strip transects were $75 \mathrm{~m}$ long and $5 \mathrm{~m}$

154 wide ( $2.5 \mathrm{~m}$ on either side of the transect line). In order to minimize disturbance, fish recording

155 and transect deployment were done simultaneously by the observers. Line transects were also 75

$156 \mathrm{~m}$ long; the perpendicular distances of individual fish (or groups of fish) from the line were

157 measured using a measuring tape, for fish detected up to $8 \mathrm{~m}$ on either side of the central line.

158 For this purpose, two divers worked together; the first was deploying the transect line and Q

159 holding the end of the measure tape ensuring that it remained vertical to the transect line, while

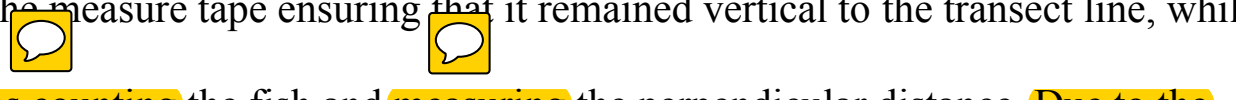

160 the second diver was counting the fish and measuring the pernendicular distance. Due to the

161 movement of fish, the distance to the original position of the fish at first detection was measured

162 (by using a fixed point of the substrate as a reference point). When individuals were observed in

163 groups, the distance of the center of the group was estimated as well as the number of

164 individuals. The swimming speed of the observer for the strip transect method was

165 approximately 3.1 meters per minute, while the corresponding speed for the line transect method

166 was 2.2 meters per minute. The survey targeted twenty fish taxa (Table 1).

\subsection{Estimating population densities}

169 In strip transects, the population mean density was estimated by the formula:

$\hat{D}=n / 2 w L=n / A_{c}$

171 n: number of individuals 
$1722 \mathrm{w}$ : total width of the transect

173 L: length of the transect

$174 \quad \mathrm{~A}_{\mathrm{c}}$ : total covered (sampled) area

175 Bootstrap (bias-corrected and accelerated with 1000 permutations) was applied to estimate, for 176 each species, the unconditional standard error (Efron and Tidshirani 1993), as well as the 95\%

177 bootstrap-based unconditional confidence interval of the mean density, using R version 3.2.3 (R

178 Development Core Team 2015).

179 For line transect data, the mean density was estimated by

$$
\hat{D}=n /\left(A_{c} P_{a}\right)
$$

181 where $P_{a}$ is the detection probability, given by:

$$
P_{a}=\frac{\int_{0}^{w} g(y) d y}{w}
$$

where $w$ is the half-width of the line transects and $g(y)$ is the detection function, representing the probability of detecting an individual that is at a distance $y$ from the transect line (Buckland et al. 185 2001).

186 The function $g(y)$ was estimated from the distance data (grouped data, right truncated at width 187 that varied from $1.2 \mathrm{~m}$ to $8 \mathrm{~m}$, depending on the dataset of each species to exclude outliers) with 188 a semi-parametric approach, according to Buckland et al. (2001), using the software DISTANCE 6.2 (Thomas et al. 2010). Specifically, the detection function was modeled in the general form:

$$
g(y)=\frac{k e y(y)[1+\operatorname{series}(y)]}{k e y(0)[1+\operatorname{series}(0)]}
$$


191 where $\operatorname{key}(y)$ is the key function and series $(y)$ is a series expansion used to adjust the key

192 function. The uniform function $k e y(y)=1 / w(0$ parameters $)$, the one parameter half normal

193 function $k e y(y)=\exp \left(-y^{2} / 2 \sigma^{2}\right)$ and the two - parameter hazard-rate function

$194 \operatorname{key}(y)=1-\exp \left[-(y / \sigma)^{-b}\right]$ were considered as key functions; three series expansions were

195 considered: the cosine series $\sum_{j=1}^{m} a_{j} \cos (j \pi y / W)$, simple polynomials of the form $\sum_{j=1}^{m} a_{j}(y / W)^{2 j}$

196 and hermite polynomials of the form $\sum_{j=2}^{m} a_{j} H_{2 j}(y / \sigma)$, where $\sigma$ and $a_{j}$ are the best-fit parameters

197 (Buckland et al. 2001).

198

199 Six models were considered for $g(y)$ : uniform key with cosine or simple polynomial series expansions, the half normal key with cosine or hermite polynomial series expansions and hazardrate key with cosine or simple polynomial series expansions, as proposed by Buckland et al.

202 (2001). Model selection was based on the Akaike's Information Criterion (AIC) (Akaike 1973).

203 The number $j$ of parameters in each series expansion was also defined using AIC between

204 models of increasing order. The model with the smallest $\mathrm{AIC}$ value $\left(\mathrm{AIC}_{\min }\right)$ was selected as the 205 'best' among the models tested. 
207

208

209

210

211

212

213

214

215

216

217

218

219

220

221

222

223

224

225

226

227

228

229

\subsection{Comparing occupancy, species richness and density estimates between strip and line} transects

The occupancy of each species (percentage of stations in which the species were recorded), species richness and population density estimates, based on the two different sampling methods were compared. Occupancy was estimated for each of the 20 species per method separately. This resulted into two distinct datasets, each consisting of 20 occupancy values; one for the line transect method and one for the strip transects method. The set of differences between line and strip transects (i.e. line transects minus strip transects) was then subjected to bootstrapping, to estimate the mean value and $95 \%$ confidence interval of the differences.

Similarly, the comparison of species richness values obtained by the two different methods (i.e. number of species present among the 20 target species) was achieved through the bootstrapping technique. Initially, species richness was estimated for each station and method separately. Consequently, two datasets of 61 species richness values each were obtained for the two methods. The set of differences when subtracting the second dataset from the first, was the actual dataset that was bootstrapped.

A similar procedure was followed for the comparison of the density estimates between the two methods. For the comparison of the 'overall densities', the mean density of each species over all stations was estimated by each method, and the differences between the two datasets (comprising of the 20 mean densities of distinct species) were bootstrapped. Additionally, the density for each species at each station was also estimated. Therefore, for each species two datasets (one for each method) with 61 values, corresponding to the number of stations, were created. The differences by subtracting the dataset of strip transects from the dataset of line transects were bootstrapped to estimate the confidence interval of the differences and test if it differed from zero. Stations in 
230 which a species was not recorded were excluded from the analysis of that species, as the aim was

231 to test for differences in the estimates of densities between the two methods when a species was

232 actually present (as inferred by at least one of the methods).

233

2342.5 Species composition

235 To investigate potential differences in species composition between the two sampling methods, a

236 Bray-Curtis similarity matrix was generated based on a square-root transformation of fish density

237 data, which was then used to carry out cluster analysis and construct a non-metric

238 multidimensional scaling (nMDS) plot. In this case, fish density data (by both methods) derived

239 only from one of the two stations of each site (31 stations in total) were used, in order to improve

240 clarity. Otherwise, the resulting MDS plot and dendrogram were too crowded (with 122 points -

24161 stations x 2 methods). Moreover, in the respective plots different colors were used for the

242 visual depiction of the station geographical position; stations marked with cold colors (shades of

243 blue) refer to areas of the northern Aegean, stations marked with warm colors

244 (yellow/orange/red) are located in the southern Aegean, while green colors denote stations found

245 in the central Aegean Sea. A SIMPER analysis based on all stations was conducted to identify

246 the species that contributed most to the observed variability between the two sampling methods.

247 The species composition analysis was carried out with PRIMER 6 software (Clarke 1993). 
251

252

253

254

255

256

257

258

259

260

261

262

263

264

265

266

267

268

269

270

271

272

273

\subsection{Distance sampling analysis}

For each species, the best model, based on AIC, was used for inference (Table 2). An empirical minimum of observations to model the detection function is 30 observations (Buckland et al. 1993). However, a number of species did not fulfill this requirement. These species were Dentex dentex, Epinephelus marginatus, Muraena helena, Sciaena umbra and Spondyliosoma cantharus. The highest detectability values (excluding species with verv low number of observations $<30$ ) were recorded for Epinephelus costae $(0.84 \pm 0.15)$ followed by Siganus<smiles>C1=CCC1</smiles>

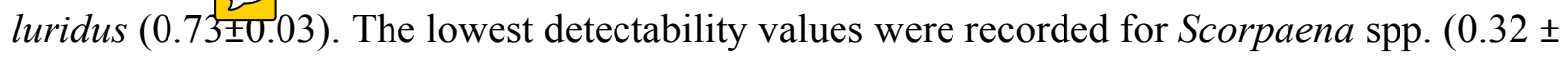
$0.05)$ and Serranus cabrilla $(0.41 \pm 0.07)$ followed by Mullus surmuletus $(0.49 \pm 0.06)$. The estimated detection probability curves corresponded to different fish behaviors (Fig. 2), according to Kulbicki (1998). Diplodus annularis, D. puntazzo, D. sargus, D. vulgaris, Oblada melanura, Sparisoma cretense, Siganus luridus and S. rivulatus exhibited 'shy behaviour', i.e. avoided the observer. M. surmuletus, E. costae, Serranus scriba, S. cabrilla and Sarpa salpa had neutral behavior, while Scorpaena spp. were secretive showing a rapid decrease in detectability within the first $0.4 \mathrm{~m}$ (Fig. 2A).

\subsection{Species Occupancy}

Across all sites, D. vulgaris was the most commonly occurring species, as it was recorded in 58 stations by both methods, while Dicentrarchus labrax was never recorded (Fig. 3). Occupancy estimates for the target species varied between the two methods; line transects gave higher estimates in 12 species, strip transects gave higher estimates in 4 species, while for three species they gave the same estimates (Fig. 3). The highest observed difference was for Scorpaena spp., with an estimated occupancy of 0.64 by line transect sampling and 0.10 by strip transect 
274 sampling. The bootstrap method, conducted to compare occupancy estimates (expressed in

275 percentages) between the two methods, showed that overall occupancy was significantly higher

276 when estimated by the line transect method (mean difference: 5.7\%; 95\% Confidence

277 Interval:1.3\%, 11.3\%).

\subsection{Species Richness}

280 Species richness (i.e. the number of species per station) was estimated stgnificantly higher in 36 281 stations by line transects and in 11 stations by strip transects, while in 14 stations no significant 282 differences were detected between the two methods (Fig. 4). The mean species richness (among 283 the 20 target species) estimated by the line transect method was 8.8, while the corresponding

284

285

286

287

288

289

290

291

292

293

294

295

296 mean species richness estimated by the strip transect method was 7.6. According to the bootstrap method, the mean difference of species richness was 0.98 species [CI: 0.57, 1.40], thus indicating significantly higher species richness estimates in line transects than strip transects.

\subsection{Density}

Fish density (i.e. number of individuals per hectare) was highly variable both among species and between methods. The overall density (i.e. mean fish density of all species) was higher for line transects than for strip transects, with a value of 166.3 and 119.0 correspondingly. The most abundant species was $D$. vulgaris, with an estimated mean value of 702.9 individuals per hectare by line transects and 567.8 individuals per hectare by strip transects. Other species with high density were $S$. salpa, O. melanura and S. luridus (Table 3, Fig. 5). D. labrax was not found in any station, and the least abundant species, among those present, was $S$. umbra with a mean density of 1.56 individuals per hectare as estimated by line transects, while no individuals were 
297 recorded in the strip transects. Other species with low density were M. helena, D. dentex and E.

298 marginatus (Table 3, Fig. 5).

299 The mean difference of the overall fish density was significantly higher for line transects than

300 for strip transects (50.5 individuals per hectare; CI [18.0, 85.7]). However, results for individual

301 species varied (Fig. 5). For this calculation, for each species only the stations for which the

302 species was detected by at least one of the methods were included. For D. sargus, D. vulgaris, D.

303 dentex, Scorpaena spp., S. cabrilla, S. scriba, S. luridus and S. rivulatus, the line transects

304 estimates were significantly higher than strip transects, while the opposite was found for $E$.

305 costae and S. cantharus. No statistically significant differences between the two methods were

306 found for D. annularis, D. puntazzo, E. marginatus, M. surmuletus, M. helena, O. melanura, S.

307 cretense and S. salpa. No comparison was possible D. labrax and S. umbra due to lack of data.

\subsection{Comparing species composition between sampling methods}

310 All data pooled, the two methods presented similar species composition, with an average

311 similarity between methods at each station of $62 \%$. Of the 31 stations presented in Fig. 6, 7 ,

312 stations 13, 27 and 15 (indicated by circles in Fig. 6.7) presented the highest resemblance (83\%,

$31381.2 \%$ and $81 \%$ respectively) whereas stations 42,48 , and 9 (indicated by lines Fig. 6,7 )

314 displayed the lowest similarity (i.e. $49.6 \%, 48 \%$, and $44 \%$ respectively). A total of 12 species

315 contributed the most to the overall differences observed between the two methods (Table 4). Of

316 these $S$. luridus, S. salpa, O. melanura and D. vulgaris, S. cretense and S. scriba accounted for

317 approximately $60 \%$ of the differences. The observed variability in species composition between

318 the two methods may partly be due to the methods per se and partly due to the between-transect

319 variability at each station. Despite the between-transect variability, a clear separation between 
320 distinct geographical regions (North and South Aegean Sea) was obvious in both methods,

321 indicating that both were consistent in depicting large-scale biogeographical patterns.

\section{Discussion}

Statistically significant differences were detected between line and strip transects in the estimates of occupancy and species richness. We suggest that the higher overall estimates of occupancy and species richness by the line transect method are mainly due to the greater width of the line transects, and thus the larger area surveyed. The use of narrow strips is dictated by the need to satisfy the assumption of perfect detectability, which is the main assumption of strip transects

331 (Katsanevakis et al. 2012). On the contrary, in line transects perfect detection is required only "on the line"; this allows expanding the width of the transects and increases the probability of recording less common species. Furthermore, the reaction of fish to the presence of the observer can be crucial for the detection of a species. Many shy species may react to divers by fleeing at distances greater than the fixed width of the strip transect, before being detected by the observers at their initial position, and hence remain unrecorded. Bozec et al. (2011) indicated that shy species display clear avoidance behavior towards divers, while the distance from the observer increases with fish size. The appropriate width of the strip transect to ensure species detection may differ even for closely related species (Kulbicki and Sarramégna 1999), or even for the same species in a different habitat (Smith and Nydegger 1985; Einsing et al. 1995; Cheal and 
341 Thompson 1997). By extending the surveyed width through the use of line transects (if there are

342 no other limitations), these sources of error can be reduced.

343 With regard to overall fish density, line transects again led to a higher estimate than strip

344 transects. This difference is partly related to fish behavior (Bozec et al. 2011; Pais and Cabral

345 2017). Kulbicki (1998) pointed out that fish are not motionless items and, in most cases, will

346 either avoid or be attracted to an observer, with the reaction sometimes changing from site to

347 site. The frequency of shy species peaks at intermediate distances because they tend to keep a

348 distance from the observer. The frequency distribution of distances for the majority of the

349 species in the present study followed the pattern of 'shy' species. In these cases, the peak of the

350 distance frequency distribution of fish observations was at distances between $0.7-2.2 \mathrm{~m}$ from

351 the line. As this peak reflects the combination of flee behavior and declining detectability with

352 distance, it is quite probable that many individuals had fled at distances much greater than the

353 observed peak. Fish behavior is therefore, a possible reason why line transects, which utilized a

354 wider surface area (i.e. $8 \mathrm{~m}$ on either side of the transect), yielded higher overall density

355 estimates compared to strip transects (i.e. $2.5 \mathrm{~m}$ on either side of the transect), because some shy

356 fish could have moved beyond the limit of the transects and thus were not recorded.

357 Nevertheless, many individuals seemed to flee at distances $<2.5 \mathrm{~m}$ and thus would have been

358 included in the strip transects.

359 Another important factor which may lead to a potential underestimation of abundance in strip

360 transects, especially for secretive species, is imperfect detectability (Franzreb 1981; Kulbicki

361 1998). The results from DISTANCE analysis showed that a sharp decline in detectability is

362 obvious at distances $>2.5 \mathrm{~m}$ from the transect line for the majority of the surveyed species.

363 Moreover, numerous studies have also shown that an obvious decline in detectability is observed 
364 at approximately $3 \mathrm{~m}$ distance from the transect (Harmelin-Vivien et al. 1985; Smith and

365 Nydegger 1985; Fowler 1987; McCormick and Choat 1987; Cheal and Thompson 1997;

366 Kulbicki and Sarramégna 1999), although this can be case-dependent. According to the above,

367 the $2.5 \mathrm{~m}$ width on each side of the strip transects used in the present study should be sufficient

368 in many cases for the detection of the majority of the target species. However, there were several

369 exceptions, such as Scorpaena spp. (Fig. 2), S. cabrilla, and S. scriba, which presented a

370 substantial decline in detectability at distances $<2.5 \mathrm{~m}$. For these latter species the density

371 estimates by line transects were substantially higher than by strip transects.

372 Although in most cases line transects yielded higher estimates, this method has additional

373 potential sources of bias. An important assumption in distance methodology is that fish should be

374 recorded prior to any movement in response to the observer. Violation of this assumption leads

375 to a negative bias in abundance estimates of 'shy' species (Buckland et al. 1993). Moreover, the

376 additional time needed to carry out the distance measurements and the actual deployment of a

377 tape-measure, may further augment the fleeing response of more mobile fish, and hence lead to

378 an underestimation of their numbers during line transects. This source of bias is considered to be

379 more intense in areas of high fish densities, since the additional time needed for measuring the

380 distance would in this case cause mare fish to be undetected (Watson et al. 1995). Finally, as

381 transects are not snapshots of species distribution but during the duration of the survey new

382 individuals may enter the sampling area, overestimation of fish density is possible. This has been

383 recently demonstrated through spatially-explicit individual-based models of fish movement

384 (Ward-Paige et al., 2010; Pais and Cabral, 2017). As line transects take more time than strip

385 transects for the same distance, at slower average speed, fish movement per se (i.e. not in

386 response to the observers) may lead to higher counts for mobile species. 
387 The multivariate analysis of the species composition indicated an overall high resemblance 388 between the two methods. In most stations the majority of the species recorded by one method 389 were also recorded by the other method, and at similar densities. These results suggest that the 390 choice of a specific method (either plot sampling or distance sampling) should not significantly 391 affect the overall outcome regarding the spatial patterns of species composition, especially in 392 large'scale studies.

Unfortunately, as is the case in most field studies, the real density values of the fish species in the

394

395

396

397

398

399

400

401

402

403

404

405

406 areas under study were not known. Therefore, it is not easy to determine which is the 'best' method by providing precise estimates of the biases related to each method per species.

According to several studies, distance sampling appears to be advantageous in many cases.

Kulbicki and Sarramégna (1999) have proposed that the use of distance sampling method in

UVS could potentially improve estimates by yielding values closer to the true values. Similarly, Einsing et al. (1995) showed that distance sampling, compared to quadrat sampling and strip transects, produced density estimates that were closer to true densities, while Thresher and Gunn (1986) proposed that distance sampling should be preferred for the assessment of secretive species. Irigoyen et al. (2018) also proposed the distance sampling as an appropriate method to survey medium- and large-sized fish species, although they also discussed some disadvantages of the specific method that should be taken into consideration. 
407

408

409

410

411

412

413

414

415

416

417

418

419

420

421

422

423

424

425

426

427

428

429

\section{Conclusion}

Both methods have several specific advantages and limitations, and both are prone to biases. Strip transects suffer from imperfect detectability and the related necessity of narrow transect widths, which may cause underestimation of densities, occupancy, and species richness. In line transect sampling, detection probability is properly taken into account, but the assumption that all individuals are detected at their initial position is difficult to satisfy, especially for fish of high mobility. Line transect sampling is expected to provide much more accurate estimates than strip transect sampling in the case of secretive species of low mobility. An additional advantage of the line transect method is that it provides a way to assess fish behavior through the analysis of distance frequency graphs. On the other hand, in the case of mobile species with neutral or close to neutral behavior, and especially at high fish densities, strip transects would probably be more efficient, as line transects are time-consuming and the disturbance of fish would be higher due to the distance measurements. The choice of the best method to apply needs careful consideration and depends on the aims of each study, the target species, and the peculiarities of the study area. Joint application of both methods could be considered, with line transects applied by one observer for secretive and large fish, and strip transects by another observer for the bulk of medium-sized mobile fish. Other approaches have been proposed when targeting multiple species with varying behaviors, such as strip transects of various sizes depending on the size and behavior of species (Minte-Vera et al., 2008; Prato et al., 2017) or the post hoc use of correction factors for each species, estimated by models, to account for behavioral patterns (assuming their consistency and replicability) (Pais and Cabral, 2017). Further research is needed to improve the performance of line transects and strip transects and reduce their biases, as well as to compare 
430 the various proposed approaches and field protocols when targeting multiple species with

431 varying behaviors.

432

433 Acknowledgements

434 We thank the following diving centers for helping to carry out the fieldwork: Aquacore Divers, 435 Athos Scuba Diving Center, Azure Diving Center, Lesvos Scuba Oceanic Center, Tortuga 436 Diving Center Mesta Chios, Mystic Blue Eco sailing and Diving.

\section{References}

Andaloro F, Castriota L, Ferraro M, Romeo T, Sara G, Consoli P (2011) Evaluating fish assemblages associated with gas platforms: evidence from a visual census technique and experimental fishing surveys. Ciencias Marinas 37:1-9 remotely operated vehicle (ROV) to study the fish community associated with offshore gas

444 platforms in the Ionian Sea: a comparative analysis with underwater visual censuses (UVCs).

445 Helgoland Marine Research 67:241-250

446 Bellwood DR (1998) On the use of visual survey methods for estimating reef fish standing 447 stocks. Fishbyte 6(1):14-16

448 Bohnsack JA and Bannerot SP (1986) A stationary visual census technique for quantitatively 449 assessing community structure of coral reef fishes. NOAA Tech Rep NMFS 41:1-15 
451 Bosch NE, Gonçalves JMS, Erzini K, Tuya F (2017) "How” and "what" matters: Sampling

452 method affects biodiversity estimates of reef fishes. Ecology and Evolution 7:4891-4906

453 Bozec YM, Kulbicki M, Laloë F, Mou-Tham G, Gascuel D (2011) Factors affecting the

454 detection distances of reef fish: implications for visual counts. Marine Biology 158:969-981

455 Buckland ST, Anderson DR, Burnham KP, Laake JL (1993) Distance Sampling: Estimating

456 Abundance of Biological Populations. Chapman and Hall, London, 446p

457 Buckland ST, Anderson DR, Burnham KP, Laake JL, Borchers DL, Thomas L (2001)

458 Introduction to distance sampling: estimating abundance of biological populations. Oxford

459 University Press, New York, NY

460 Buckland ST, Anderson DR, Burnham KP, Laake JL Borchers DL, Thomas L (2004) Advanced

461 Distance Sampling: Estimating Abundance of Biological Populations. Oxford University Press,

462 New York

463 Burnham KP, Anderson DR (1984) The need for distance data in transect counts. Journal of

464 Wildlife Management 48: 1248-1254.

465 Caldwell ZR, Zgliczynski BJ, Williams GJ, Sandin SA (2016) Reef fish survey techniques:

466 assessing the potential for standardizing methodologies. PLoS ONE 11(4): e0153066.

467 https://doi.org/10.1371/journal.pone.0153066

468 Cheal AJ, Thompson AA (1997) Comparing visual counts of coral reef fish: implications of

469 transect width and species selection. Marine Ecology Progress Series 158:241-248

470 Clarke KR, Gorley RN (2006) PRIMER v6: User Manual/Tutorial. PRIMER-E, Plymouth, $471 \quad 192 \mathrm{pp}$ 
472 Clarke KR (1993) Non-parametric multivariate analyses of changes in community structure.

473 Australian Journal of Ecology 18:117-143

474 Côté IM, Perrow MR (2006) Fish. In: Sutherland WJ (ed) Ecological Census Techniques: A

475 Handbook, 2nd ed. Cambridge University Press, Cambridge

476 Edgar GJ, Barrett NS (1999) Effects of the declaration of marine reserves on Tasmanian reef

477 fishes, invertebrates and plants. Journal of Experimental Marine Biology and Ecology 242:107-

$478 \quad 144$

479 Edgar GJ, Barrett NS, Morton AJ (2004) Biases associated with the use of underwater visual 480 census techniques to quantify the density and size structure of fish populations. Journal of 481 Experimental Marine Biology and Ecology 308:269-290

482 Efron B, Tibshirani RJ (1993) An introduction to the bootstrap. Chapman and Hall, New-York

483 Ensign WE, Angermeier PL, Dollof CA (1995) Use of line transect methods to estimate

484 abundance of benthic stream fishes. Canadian Journal of Fisheries and Aquatic Sciences 52:213$485 \quad 222$

486 Fewster RM, Southwell C, Borchers DL, Buckland ST, Pople AR (2008) The influence of 487 animal mobility on the assumption of uniform distances in aerial line transect surveys. Wildlife 488 Research 35:275-288

489 Fowler AJ (1987) The development of sampling strategies for population studies of coral reef 490 fishes. A case study. Coral Reefs 6:49-58 
491 Franzreb KE (1981) The determination of avian densities using the variable-strip and fixed-width

492 transect surveying methods. In: Ralph CJ and Scott JM (eds) Estimating Numbers of terrestrial

493 Birds, Studies in Avian Biology 6. Allen Press, Lawrence

494 Friedlander AM, Donovan MK, Stamoulis KA, Williams ID, Brown EK, Conklin EJ, DeMartini

495 EE, Rodgers KS, Sparks RT, Walsh WJ (2018). Human-induced gradients of reef fish declines in 496 the Hawaiian archipelago viewed through the lens of traditional management boundaries.

497 Aquatic Conservation: Marine and Freshwater Ecosystems 28: 146-157

498 Harmelin-Vivien ML, Harmelin JG, Chauvet C, Duval C, Galzin R, Lejeune P, Barnabé G, 499 Blanc F, Chevalier R, Duclerc J, Lasserre G (1985) Evaluation visuelle des peuplements et 500 populations de poissons: méthodes et problems. Revue d' Ecologie (Terre Vie) 40:467-539

501 Hill J, Wilkinson C (2004) Methods for Ecological Monitoring of Coral Reefs. Australian 502 Institute of Marine Science, Townsville

503 Holmes TH, Wilson SK, Travers MJ, Langlois TJ, Evans RD, Moore GI, Douglas RA, Shedrawi 504 G, Harvey ES, Hickey K (2013) A comparison of visual- and stereo-video based fish community 505 assessment methods in tropical and temperate marine waters of Western Australia. Limnology 506 Oceanography 11:337-350

507 Horton T, Kroh A, Bailly N, Boury-Esnault N, Brandão SN, Costello MJ, Gofas S, Hernandez F, 508 Mees J, Paulay G, Poore GCB, Rosenberg G, Decock W, Dekeyzer S, Lanssens T, Vandepitte L, 509 Vanhoorne B, Verfaille K, Adlard R, Adriaens P, Agatha S, Ahn KJ, Akkari N, Alvarez B, 510 Anderson G, Angel M, Arango C, Artois T, Atkinson S, Bank R, Barber A, Barbosa JP, Bartsch

511 I, Bellan-Santini D, Bernot J, Berta A, Bieler R, Blanco S, Blasco-Costa I, Blazewicz M, Bock P, 512 Böttger-Schnack R, Bouchet P, Boxshall G, Boyko CB, Bray R, Breure B, Bruce NL, Cairns S, 
513 Campinas Bezerra TN, Cárdenas P, Carstens E, Chan BK, Chan TY, Cheng L, Churchill M,

514 Coleman CO, Collins AG, Corbari L, Cordeiro R, Cornils A, Coste M, Crandall KA, Cribb T,

515 Cutmore S, Dahdouh-Guebas F, Daly M, Daneliya M, Dauvin JC, Davie P, De Broyer C, De

516 Grave S, de Mazancourt V, de Voogd N, Decker P, Decraemer W, Defaye D, d'Hondt JL,

517 Dijkstra H, Dohrmann M, Dolan J, Domning D, Downey R, Drapun I, Ector L, Eisendle-

518 Flöckner U, Eitel M, Encarnação SCd, Enghoff H, Epler J, Ewers-Saucedo C, Faber M, Feist S,

519 Figueroa D, Finn J, Fišer C, Fordyce, E, Foster W, Frank JH, Fransen C, Furuya H, Galea H

520 Garcia-Alvarez O, Garic R, Gasca R, Gaviria-Melo S, Gerken S, Gheerardyn H, Gibson D, Gil J,

521 Gittenberger A, Glasby G, Glover A, Gómez-Noguera SE, González-Solís D, Gordon D,

522 Grabowski M, Gravili C, Guerra-García JM, Guidetti R, Guiry MD, Hadfield KA, Hajdu E,

523 Hallermann J, Hayward B, Hendrycks E, Herbert D, Herrera Bachiller A, Ho Js, Høeg J,

524 Hoeksema B, Holovachov O, Hooper J, Houart R, Hughes L, Hyžný M, Iniesta LFM, Iseto T,

525 Ivanenko S, Iwataki M, Jarms G, Jaume D, Jazdzewski K, Jóźwiak P, Kantor Y, Karanovic I,

526 Karthick B, Kim YH, King R, Kirk PM, Klautau M, Kociolek JP, Köhler F, Kolb J, Kotov A,

527 Krapp-Schickel T, Kremenetskaia A, Kristensen R, Kulikovskiy M, Kullander S, La Perna R,

528 Lambert G, Lazarus D, Le Coze F, LeCroy S, Leduc D, Lefkowitz EJ, Lemaitre R, Liu Y, Lörz

529 AN, Lowry J, Ludwig T, Lundholm N, Macpherson E, Madin L, Mah C, Mamos T, Manconi R,

530 Mapstone G, Marek PE, Marshall B, Marshall DJ, Martin P, McInnes S, Meidla T, Meland K,

531 Merrin K, Mesibov R, Messing C, Miljutin D, Mills C, Moestrup Ø, Mokievsky V, Molodtsova

532 T, Monniot F, Mooi R, Morandini AC, Moreira da Rocha R, Moretzsohn F, Mortelmans J,

533 Mortimer J, Musco L, Neubauer TA, Neubert E, Neuhaus B, Ng P, Nguyen AD, Nielsen C,

534 Nishikawa T, Norenburg J, O'Hara T, Opresko D, Osawa M, Ota Y, Páll-Gergely B, Patterson D,

535 Paxton H, Peña Santiago R, Perrier V, Perrin W, Petrescu I, Picton B, Pilger JF, Pisera A, 
536 Polhemus D, Potapova M, Pugh P, Read G, Reimer JD, Reip H, Reuscher M, Reynolds JW,

537 Richling I, Rimet F, Ríos P, Rius M, Rogers DC, Rützler K, Rzhavsky A, Sabbe K, Saiz-Salinas

538 J, Sala S, Santos S, Sar E, Sartori AF, Satoh A, Schatz H, Schierwater B, Schmidt-Rhaesa A,

539 Schneider S, Schönberg C, Schuchert P, Senna AR, Serejo C, Shaik S, Shamsi S, Sharma J,

540 Shear WA, Shenkar N, Shinn A, Short M, Sicinski J, Siegel V, Sierwald P, Simmons E, Sinniger

541 F, Sivell D, Sket B, Smit H, Smit N, Smol N, Souza-Filho JF, Spelda J, Sterrer W, Stienen E,

542 Stoev P, Stöhr S, Strand M, Suárez-Morales E, Summers M, Suttle C, Swalla BJ, Taiti S, Tanaka

543 M, Tandberg AH, Tang D, Tasker M, Taylor J, Taylor J, Tchesunov A, ten Hove H, ter Poorten

544 JJ, Thomas J, Thuesen EV, Thurston M, Thuy B, Timi JT, Timm T, Todaro A, Turon X, Tyler S,

545 Uetz P, Utevsky S, Vacelet J, Vachard D, Vader W, Väinölä R, Van de Vijver B, van der Meij

546 SE, van Haaren T, van Soest R, Van Syoc R, Vanreusel A, Venekey V, Vinarski M, Vonk R,

547 Vos C, Walker-Smith G, Walter TC, Watling L, Wayland M, Wesener T, Wetzel C, Whipps C,

548 White K, Williams D, Williams G, Wilson R, Witkowski A, Witkowski J, Wyatt N, Wylezich C, 549 Xu K, Zanol J, Zeidler W, Zhao Z (2018) World Register of Marine Species. Available from

550 http://www.marinespecies.org at VLIZ (accessed 2 May 2018) doi:10.14284/170

551 Irigoyen AJ, Rojo I, Calò A, Trobbiani G, Sánchez-Carnero N, García-Charton JA (2018) The

552 "Tracked Roaming Transect" and distance sampling methods increase the efficiency of

553 underwater visual censuses. PLOS ONE 13(1): e0190990. Available at

554 https://doi.org/10.1371/journal.pone.0190990

555 Katsanevakis S (2009) Estimating abundance of endangered marine benthic species using

556 Distance Sampling through SCUBA diving: the Pinna nobilis (Mollusca: Bivalvia) example. In:

557 Columbus AM, Kuznetsov L (eds) Endangered Species: New Research. Nova Science, New

558 York, NY, p 81-115 
559 Katsanevakis S, Weber A, Pipitone C, Leopold M and others (2012) Monitoring marine

560 populations and communities: methods dealing with imperfect detectability. Aquatic Biology

$561 \quad 16: 31-52$

562 Kulbicki M (1998) How the acquired behaviour of commercial reef fishes may influence the

563 results obtained from visual censuses. Journal of Experimental Marine Biology and Ecology

$564 \quad 222: 11-30$

565 Kulbicki M, Sarramégna S (1999) Comparison of density estimates derived from strip transect

566 and distance sampling for underwater visual censuses: a case study of Chaetodontidae and

567 Pomacanthidae. Aquatic Living Resources 12:315-325

568 Labrosse P, Kulbicki M and Ferraris J (2002) Underwater visual fish census surveys: Proper use 569 and implementation. Secretariat of the Pacific Community

570 Lessios HA (1996) Methods for quantifying abundance of marine organisms. In: MA Lang CB,

571 editor; The Diving for Science (1996), "Methods and Techniques of Underwater Research",

572 Proceedings of the American Academy of Underwater Sciences Sixteenth Annual Scientific

573 Diving Symposium, Smithsonian Institution, Washington, DC. 9

574 McCormick MI, Choat JH (1987) Estimating total abundance of a large temperate-reef fish using

575 visual strip transects. Marine Biology 96:469-478

576 MacNeil MA, Graham NAJ, Conroy MJ, Fonnesbeck CJ, Polunin NVC, Rushton SP, Chabanet

577 P, McClanahan TR (2008a) Detection heterogeneity in underwater visual census data. Journal of

578 Fish Biology 73:1748-1763 
579 MacNeil MA, Tyler EHM, Fonnesbeck CJ, Rushton SP, Polunin NVC, Conroy MJ (2008b)

580 Accounting for detectability in reef-fish biodiversity estimates. Marine Ecology Progress Series

$581 \quad 367: 249-260$

582 Mapstone BD, Ayling AM (1993) An investigation of optimum methods and unit sizes for the

583 visual estimation of abundances of some coral reef organisms. A report to the Great Barrier Reef

584 Marine Park Authority, Townsville, Australia

585 Minte-Vera CV, Leão de Moura R, Francini-Filho RB, 2008. Nested sampling: an improved

586 visual-census technique for studying reef fish assemblages. Marine Ecology Progress Series 367:

$587 \quad 283-293$

588 Monk J (2014) How long should we ignore imperfect detection of species in the marine

589 environment when modelling their distribution? Fish and Fisheries 15:352-358

590 Pais MP, Cabral HN (2017) Fish behavior effects on the accuracy and precision of underwater

591 visual surveys. A virtual ecologist approach using an individual-based model. Ecological

592 Modelling 346:58-69

593 Petza D, Maina I, Koukourouvli N, Dimarchopoulou D, Akrivos D, Kavadas S, Tsikliras AC,

594 Karachle PK, Katsanevakis S (2017). Where not to fish - reviewing and mapping fisheries

595 restricted areas in the Aegean Sea. Mediterranean Marine Science 18: 310-323.

596 Prato G, Thiriet P, Di Franco A, Francour P (2017) Enhancing fish Underwater Visual Census to

597 move forward assessment of fish assemblages: An application in three Mediterranean Marine

598 Protected Areas. PLoS ONE 12(6): e0178511. https://doi.org/10.1371/journal.pone.0178511 
599 R Core Team (2015). R: A language and environment for statistical computing. R Foundation for 600 Statistical Computing, Vienna, Austria. URL https:/www.R-project.org/

601 Rotherham D, Underwood AJ, Chapman MG, Gray CA (2007) A strategy for developing 602 scientific sampling tools for fishery-independent surveys of estuarine fish in New South Wales, 603 Australia. ICES Journal of Marine Science 64:1512- 1516

604 Sale PF, Sharp BJ (1983) Correction for bias in visual transect census of coral reef fishes. Coral 605 Reefs 2:37-42

606 Samoilys MA, Carlos G (2000) Determining methods of underwater visual census for estimating 607 the abundance of coral reef fishes. Environmental Biology of Fishes 57(3):289-304

608 Smith GW, Nydegger NC (1985) A spot-light, line transect method for surveying jack rabbits.

609 Journal of Wildlife Management 49:699-702

610 Thomas L, Buckland ST, Rexstad E, Laake JL, Strindberg S, Hedley SL, Bishop JRB, Marques

611 TA, and Burnham KP (2010) Distance software: design and analysis of distance sampling

612 surveys for estimating population size. Journal of Applied Ecology 47:5-14

613 Thompson AA, Mapstone BD (1997) Observer effects and training in underwater visual surveys 614 of reef fishes. Marine Ecology Progress Series 154:53-63

615 Thresher RE, Gunn JS (1986) Comparative analysis of visual census techniques for highly 616 mobile, reef-associated piscivores (Carangidae). Environmental Biology of Fishes 17:93-116

617 Ward-Paige CA, Flemming JM, Lotze HK (2010) Overestimating fish counts by non-

618 instantaneous visual censuses: consequences for population and community descriptions. PLoS

619 One 5: e11722. http://dx.doi.org/10.1371/journal.pone.0011722. 
620 Watson RA, Carlos GM, Samoylis MA (1995) Bias introduced by the non-random movement of

621 fish in visual transect surveys. Ecological Modelling 77:205-214

622

623 


\section{Table $\mathbf{1}$ (on next page)}

Fish taxa surveyed (according to Horton et al. 2017)

Scorpaena spp. include the species Scorpaena porcus, Scorpaena scrofa and Scorpaena notata, which cannot be easily distinguished in situ. 
1

\begin{tabular}{|ccc|}
\hline Family & Species & Authority \\
Moronidae & Dicentrachus labrax & (Linnaeus, 1758) \\
Mullidae & Mullus surmuletus & Linnaeus, 1758 \\
Muraeninae & Muraena helena & Linnaeus, 1758 \\
Scaridae & Sparisoma cretense & (Linnaeus, 1758) \\
Scianidae & Sciaena umbra & Linnaeus, 1758 \\
Scorpaenidae & Scorpaena spp. & Linnaeus, 1758 \\
Serranidae & Epinephelus costae & (Lindachner, 1878) \\
Serranidae & Epinephelus marginatus & (Linnaeus, 1758) \\
Serranidae & Serranus cabrilla & (Linnaeus, 1758) \\
Serranidae & Serranus scriba & (Rüppell, 1829) \\
Siganidae & Siganus luridus & Forsskål \& Niebuhr, 1775 \\
Siganidae & Siganus rivulatus & (Linnaeus, 1758) \\
Sparidae & Dentex dentex & (Linnaeus, 1758) \\
Sparidae & (Walbaum, 1792) \\
Sparidae & Diplodus annularis & (Linnaeus, 1758) \\
Sparidae & Diplodus puntazzo & (Geoffroy Saint- Hilaire,1817) \\
Sparidae & Diplodus sargus & (Linnaeus, 1758) \\
Sparidae & Diplodus vulgaris & (Linnaeus, 1758) \\
Sparidae & Oblada melanura & (Linnaeus, 1758) \\
Sparidae & Sarpa salpa & \\
\hline
\end{tabular}

2 


\section{Table 2 (on next page)}

Best fit model, maximum width of line transect after truncation (w) and value of detectability $(\mathrm{Pa})$ of the DISTANCE analysis for each species.

Best fit model, maximum width of line transect after truncation $(w)$ and value of detectability along with the SE $\left(P_{a} \pm \mathrm{SE}\right)$ of the DISTANCE analysis for each species. For species marked with ' $*$ ', reasonable results were not obtained due to lack of sufficient observations. 


\begin{tabular}{|c|c|c|c|}
\hline Species & Model & $W \max (m)$ & $P_{a}(\mathrm{SE})$ \\
\hline Disentrachus labrax & - & - & - \\
\hline Mullus surmuletus & $\begin{array}{c}\text { Hazard rate, simple polynomial of } \\
\text { order } 2\end{array}$ & 8.0 & $0.49 \pm 0.06$ \\
\hline Muraena helena * & Half normal, cosine of order 1 & 4.2 & $0.99 \pm 0.72$ \\
\hline Sparisoma cretense & $\begin{array}{c}\text { Hazard rate, simple polynomial of } \\
\text { order } 2\end{array}$ & 6.0 & $0.79 \pm 0.03$ \\
\hline Sciaena umbra * & Half normal, cosine of order 1 & 1.4 & $0.99 \pm 0.75$ \\
\hline Scorpaena spp. & Half normal, cosine of order 2 & 1.2 & $0.32 \pm 0.05$ \\
\hline Epinephelus costae & Hazard rate, hermite of order 2 & 6.5 & $0.84 \pm 0.15$ \\
\hline Epinephelus marginatus * & Uniform, cosine of order 1 & 7.0 & $0.58 \pm 0.09$ \\
\hline Serranus cabrilla & $\begin{array}{c}\text { Hazard rate, simple polynomial of } \\
\text { order } 1\end{array}$ & 5.0 & $0.41 \pm 0.07$ \\
\hline Serranus scriba & Half normal, hermite of order 1 & 6.0 & $0.54 \pm 0.04$ \\
\hline Siganus luridus & $\begin{array}{c}\text { Hazard rate, simple polynomial of } \\
\text { order } 2\end{array}$ & 6.0 & $0.73 \pm 0.03$ \\
\hline Siganus rivulatus & Uniform, cosine of order 1 & 6.3 & $0.56 \pm 0.05$ \\
\hline Dentex dentex * & Uniform & 7.3 & $1.00 \pm 0.48$ \\
\hline Diplodus annularis & $\begin{array}{c}\text { Hazard rate, simple polynomial of } \\
\text { order } 2\end{array}$ & 6.9 & $0.57 \pm 0.04$ \\
\hline Diplodus puntazzo & Uniform, cosine of order 1 & 6.9 & $0.60 \pm 0.04$ \\
\hline Diplodus sargus & Hazard rate, cosine of order 2 & 6.8 & $0.64 \pm 0.09$ \\
\hline Diplodus vulgaris & Uniform, cosine of order 2 & 7.0 & $0.66 \pm 0.04$ \\
\hline Oblada melanura & $\begin{array}{c}\text { Hazard rate, simple polynomial of } \\
\text { order } 2\end{array}$ & 7.6 & $0.66 \pm 0.04$ \\
\hline Sarpa salpa & $\begin{array}{c}\text { Hazard rate, simple polynomial of } \\
\text { order } 2\end{array}$ & 6.0 & $0.67 \pm 0.05$ \\
\hline Spondyliosoma cantharus * & Uniform & 6.7 & $1.00 \pm 0.38$ \\
\hline
\end{tabular}

1

2

3

4

5

6

7 


\section{Table 3(on next page)}

Mean population densities and $95 \%$ confidence intervals for all species per sampling method (line or strip transects). 


\begin{tabular}{|c|c|c|c|c|}
\hline \multirow{3}{*}{ Species } & \multicolumn{4}{|c|}{ Method } \\
\hline & \multicolumn{2}{|c|}{ Line } & \multicolumn{2}{|c|}{ Strip } \\
\hline & $\begin{array}{c}\text { Mean } \\
\text { (individuals/ha) }\end{array}$ & $95 \% \mathrm{CI}$ & $\begin{array}{c}\text { Mean } \\
\text { (individuals/ha) }\end{array}$ & $95 \% \mathrm{CI}$ \\
\hline Disentrachus labrax & 0.0 & $0.0-0.0$ & 0.0 & $0.0-0.0$ \\
\hline Mullus surmuletus & 48.5 & $35.3-62.5$ & 44.9 & $31.0-61.2$ \\
\hline Muraena helena & 2.3 & $1.1-4.1$ & 0.8 & $0.0-1.7$ \\
\hline Sparisoma cretense & 252.3 & $192.5-317.1$ & 243.0 & $177.4-312.6$ \\
\hline Sciaena umbra & 1.6 & $0.0-3.9$ & 0.0 & $0.0-0.0$ \\
\hline Scorpaena spp. & 178.0 & $127.4-234.1$ & 4.3 & $1.3-7.8$ \\
\hline Epinephelus costae & 13.1 & $6.1-20.8$ & 21.3 & $10.0-33.6$ \\
\hline Epinephelus. marginatus & 4.8 & $2.5-7.6$ & 5.2 & $1.7-10.4$ \\
\hline Serranus cabrilla & 85.2 & $60.7-110.3$ & 63.4 & $44.1-85.6$ \\
\hline Serranus scriba & 232.1 & $184.2-282.5$ & 167.1 & 129.3-208.9 \\
\hline Siganus luridus & 529.9 & $380.5-662.3$ & 281.4 & $198.0-372.5$ \\
\hline Siganus rivulatus & 189.1 & $102.3-281.3$ & 40.7 & $15.7-69.5$ \\
\hline Dentex dentex & 8.5 & $1.8-17$ & 1.2 & $0.0-3.0$ \\
\hline Diplodus annularis & 100.7 & $72.5-132.7$ & 87.8 & $55.9-124.6$ \\
\hline Diplodus puntazzo & 39.0 & $26.7-53.1$ & 33.5 & $23.6-44.1$ \\
\hline Diplodus sargus & 158.5 & $121.8-196.7$ & 72.5 & $56.8-89.1$ \\
\hline Diplodus vulgaris & 703.5 & $606.9-803$ & 568.6 & $472.5-672.3$ \\
\hline Oblada melanura & 312.8 & $241.5-382.2$ & 319.7 & $197.5-456.4$ \\
\hline Sarpa salpa & 421.1 & $321.4-525.3$ & 381.7 & $290.2-478.7$ \\
\hline Spondyliosoma cantharus & 3.5 & $1.6-5.8$ & 40.0 & $11.8-79.1$ \\
\hline Overall density & 166.3 & $1.5-534.0$ & 119.0 & $0.0-391.8$ \\
\hline
\end{tabular}

1 


\section{Table 4 (on next page)}

Summary of similarity percentage analysis (SIMPER) listing species that cumulatively contribute $90 \%$ to the dissimilarity (Bray Curtis) of the two underwater visual sampling methods based on square-root transformed density data.

Av. Diss.: Average dissimilarity, Diss/SD: Dissimilarity to standard deviation ratio, Contrib.\%:

Percentage contribution of the different species to the overall dissimilarity, Cum.\%:

Cumulative percentage contribution of the different species to the overall dissimilarity. 
1

2 Species

3

Siganus luridus

Sarpa salpa

$4 \quad$ Oblada melanura

Diplodus vulgaris

5 Sparisoma cretense

Serranus scriba

Scorpaena spp.

Diplodus annularis

Diplodus sargus

8 Siganus rivulatus

Serranus cabrilla

9 Mullus surmuletus

Line transect Strip transect

Average dissimilarity $=53.45 \%$

Av.Diss. Diss./SD Contrib.\% Cum.\%

6.52

1.11

12.20

12.20

5.95

1.26

$11.13 \quad 23.32$

5.57

1.26

$10.42 \quad 33.75$

4.89

1.24

9.15

42.90

4.60

1.26

8.60

51.49

3.64

1.24

6.81

58.30

3.22

0.92

6.02

64.32

1.11

5.72

70.04

2.99

1.32

5.59

75.63

2.85

0.63

5.34

80.97

2.79

1.11

5.21

86.18

2.14

1.12

4.01

90.19

10

11

12

13

14 


\section{Figure 1}

Map of the sampling area depicting the different sites and the code numbers of sampling stations.

The inset depicts the study area within the Mediterranean Sea.

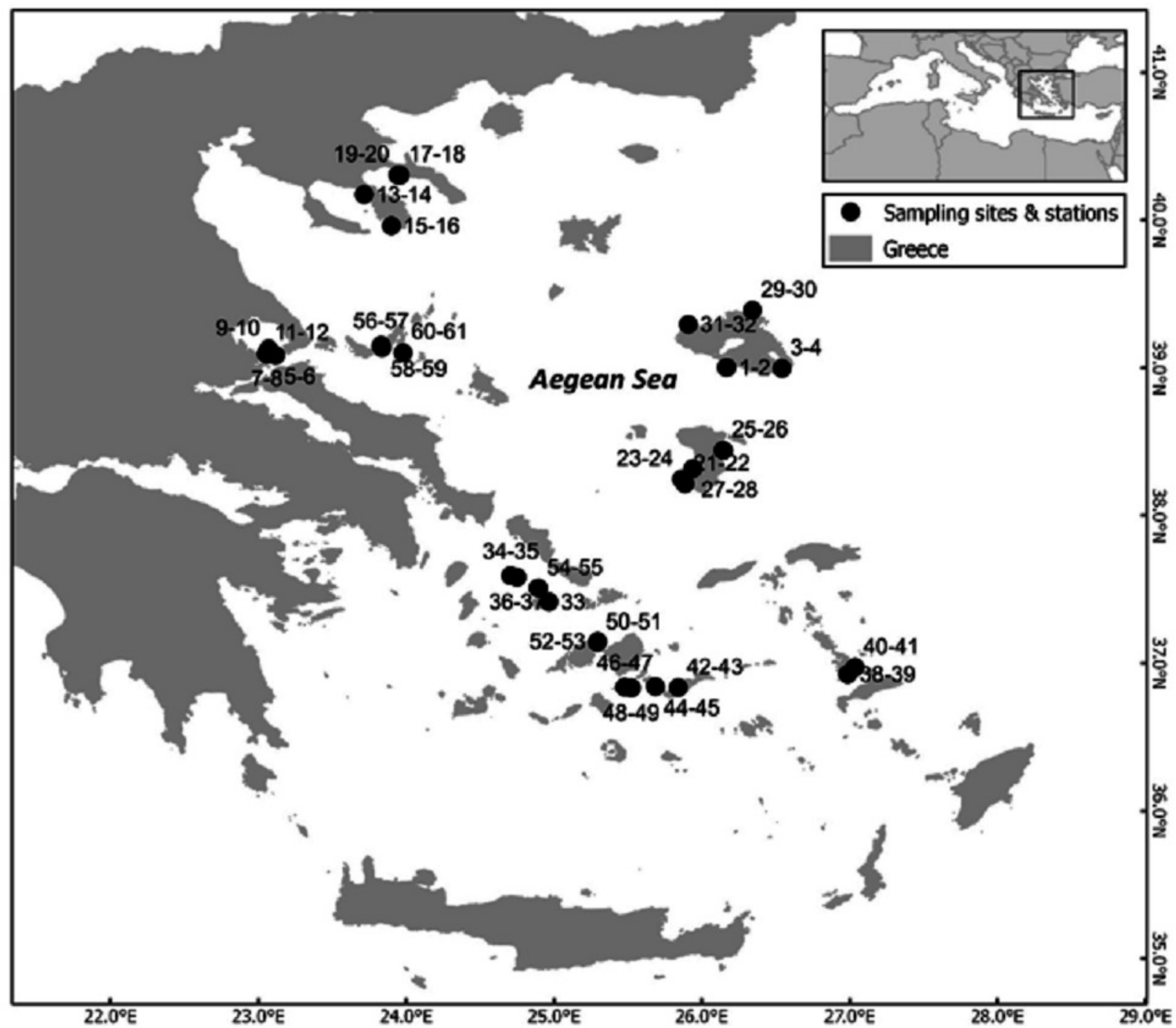




\section{Figure 2}

Detection probability curves (lines, left ordinate) estimated for three species recorded in line transects illustrating various fish behaviors

Detection probability curves (lines, left ordinate) estimated for three species recorded in line transects illustrating (A) secretive behaviour (Scorpaena spp.), (B) shy behavior (Diplodus annularis) and (C) neutral behavior (Epinephelus costae). Bars (right ordinate) represent the frequency of observations in equal distance classes. The numbers above the bars indicate the number of recorded individuals at each distance class. 


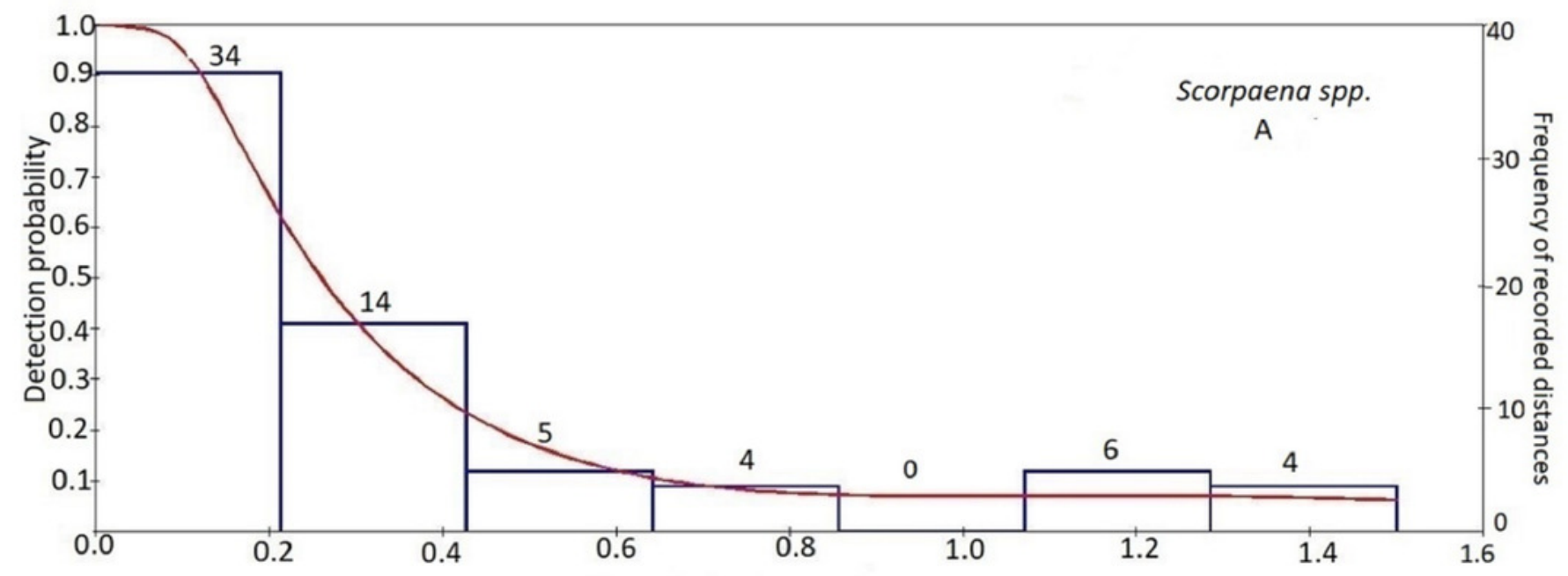

Perpendicular distance in meters
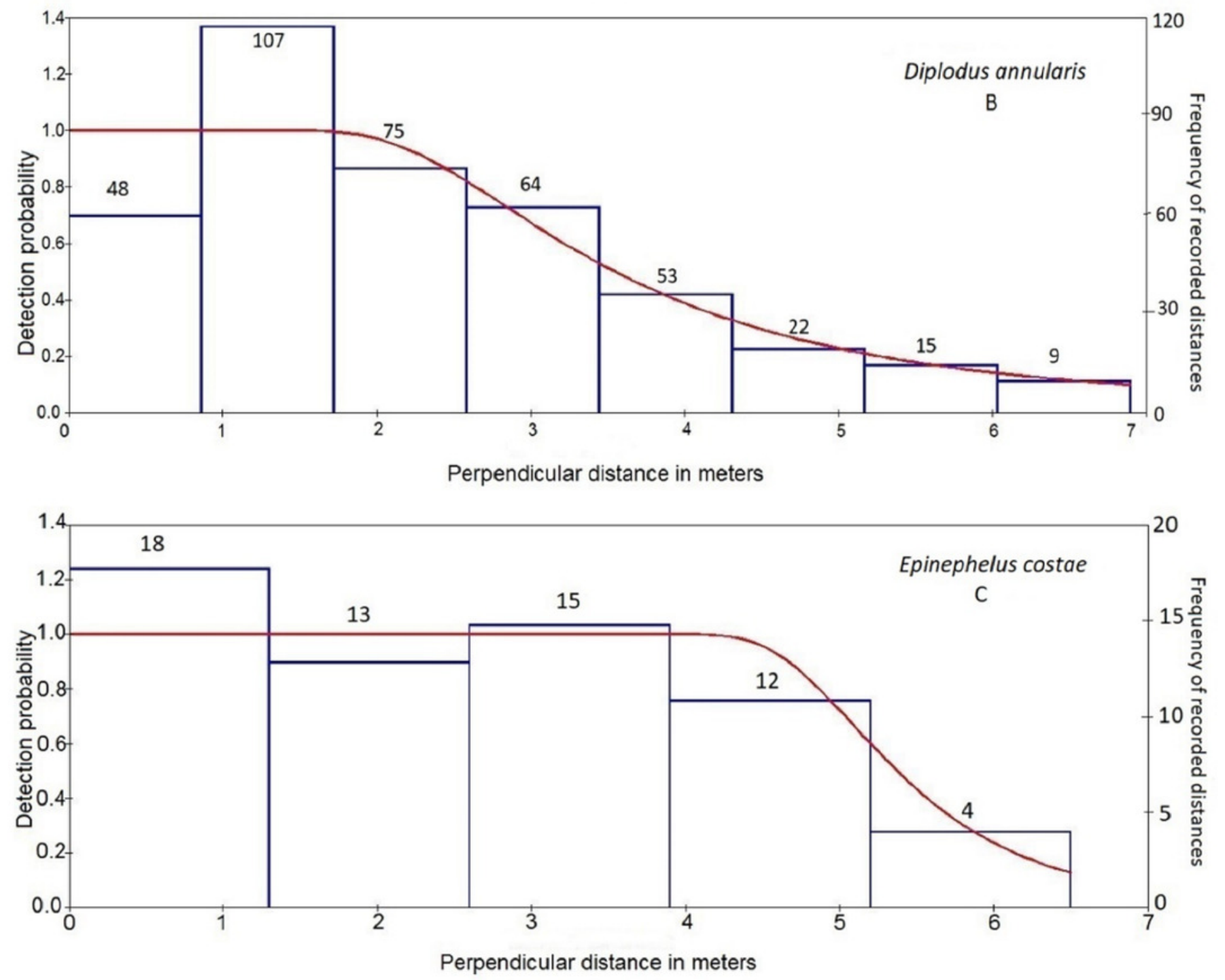


\section{Figure 3}

Occupancy estimates per species and per method, expressed as the total number of stations in which the species was present.

Occupancy estimates per species and per method, expressed as the total number of stations in which the species was present (numbers next to the bars), based on surveys by the line (black color/top bar) and strip (blue color/bottom bar) transects methods. The last two bars indicate the mean estimated occupancy of all spec per method. The total number of stations was 61 . The last two bars indicate the mean occupancy per method.

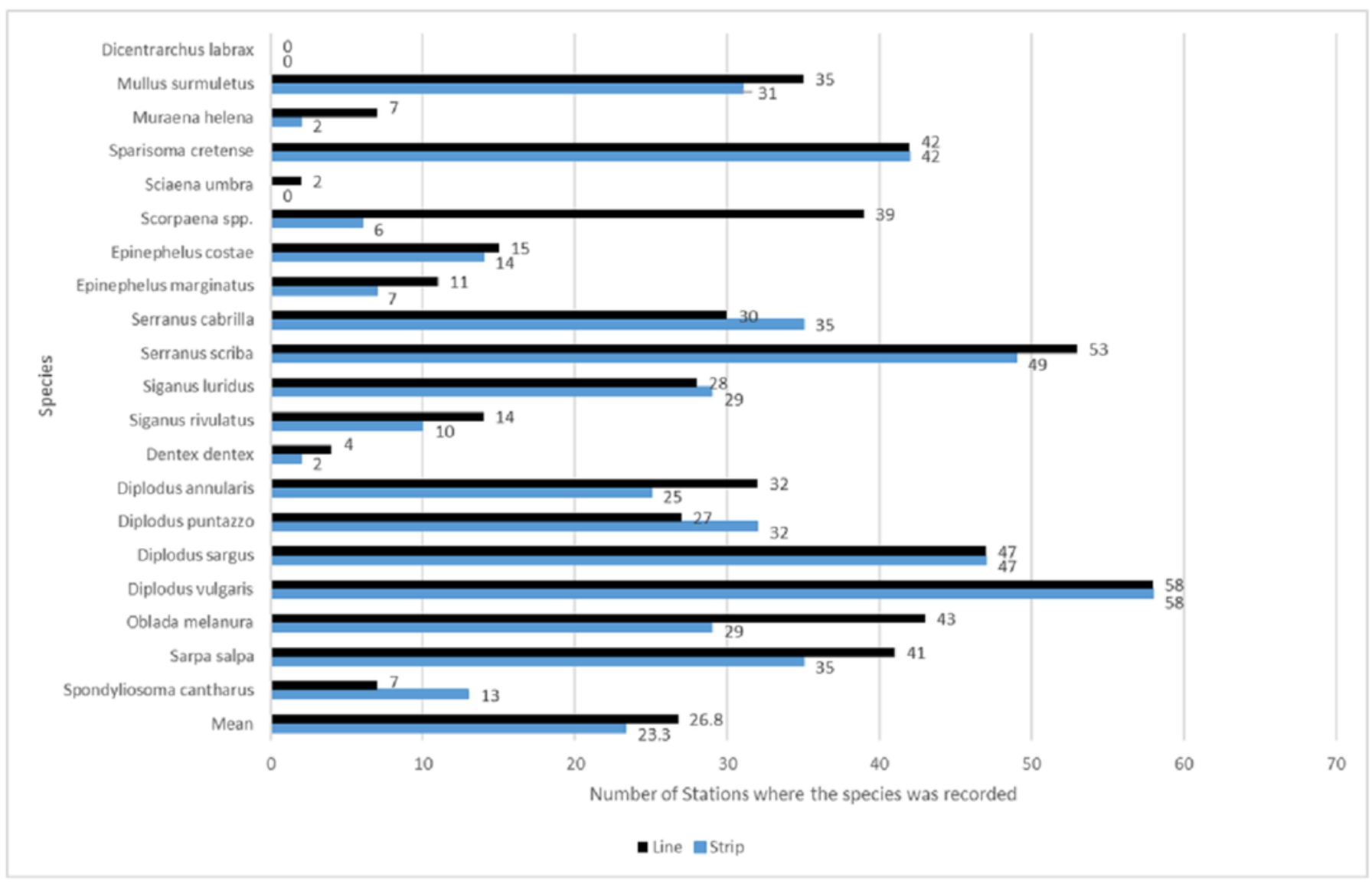


Figure 4

Histogram of the differences in estimated species richness by the line and strip transects methods.

For the calculation, strip transect richness was subtracted from line transect.

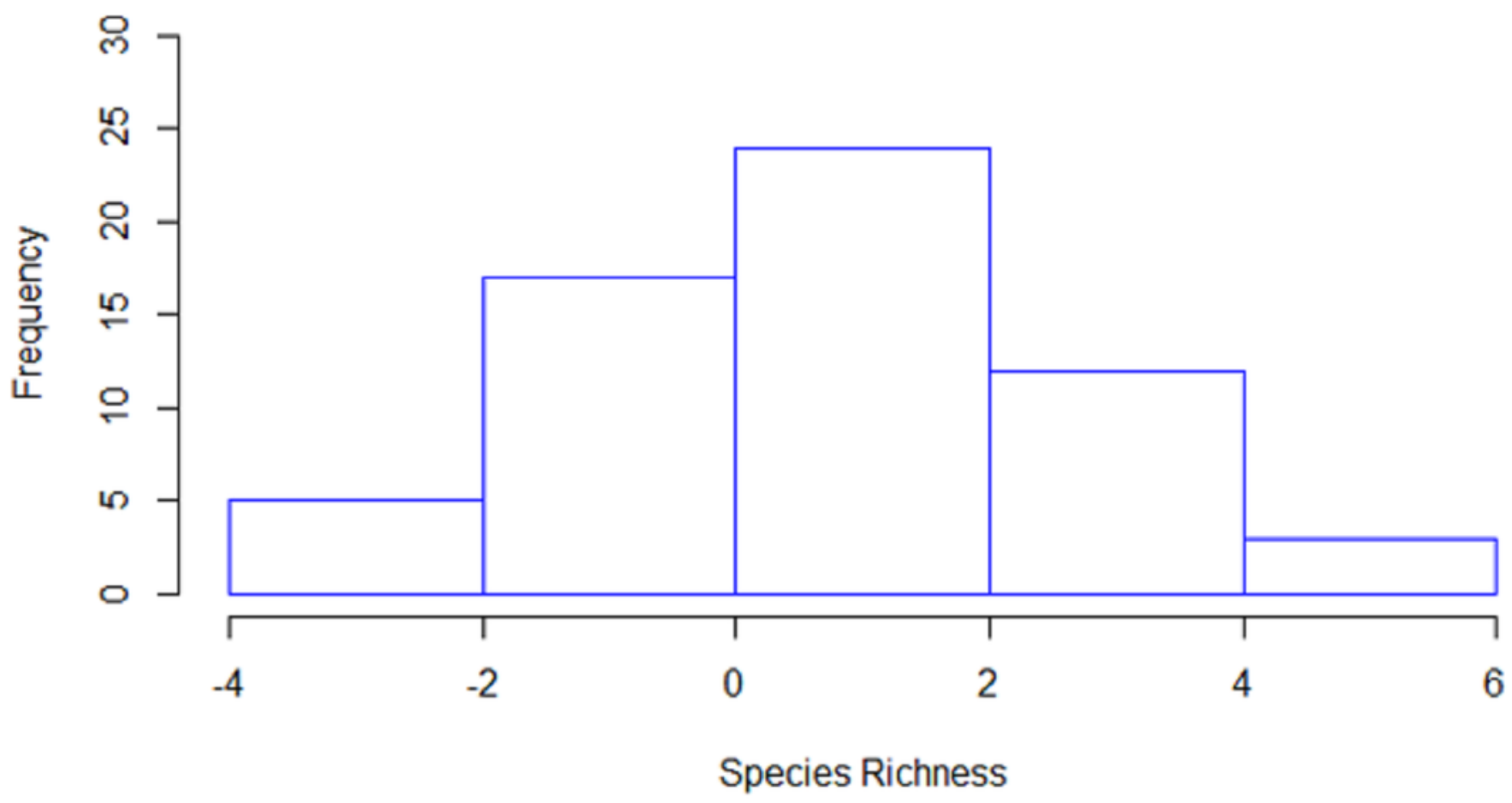


Figure 5

Mean differences of density estimates for each species (with Confidence Intervals)

Mean differences of density estimates for each species. The bars depict the $95 \%$ Confidence Intervals. The numbers above each point represent the sample size (i.e. the number of stations where the species was present with any of the two methods, when the overall sample size is 61 stations).

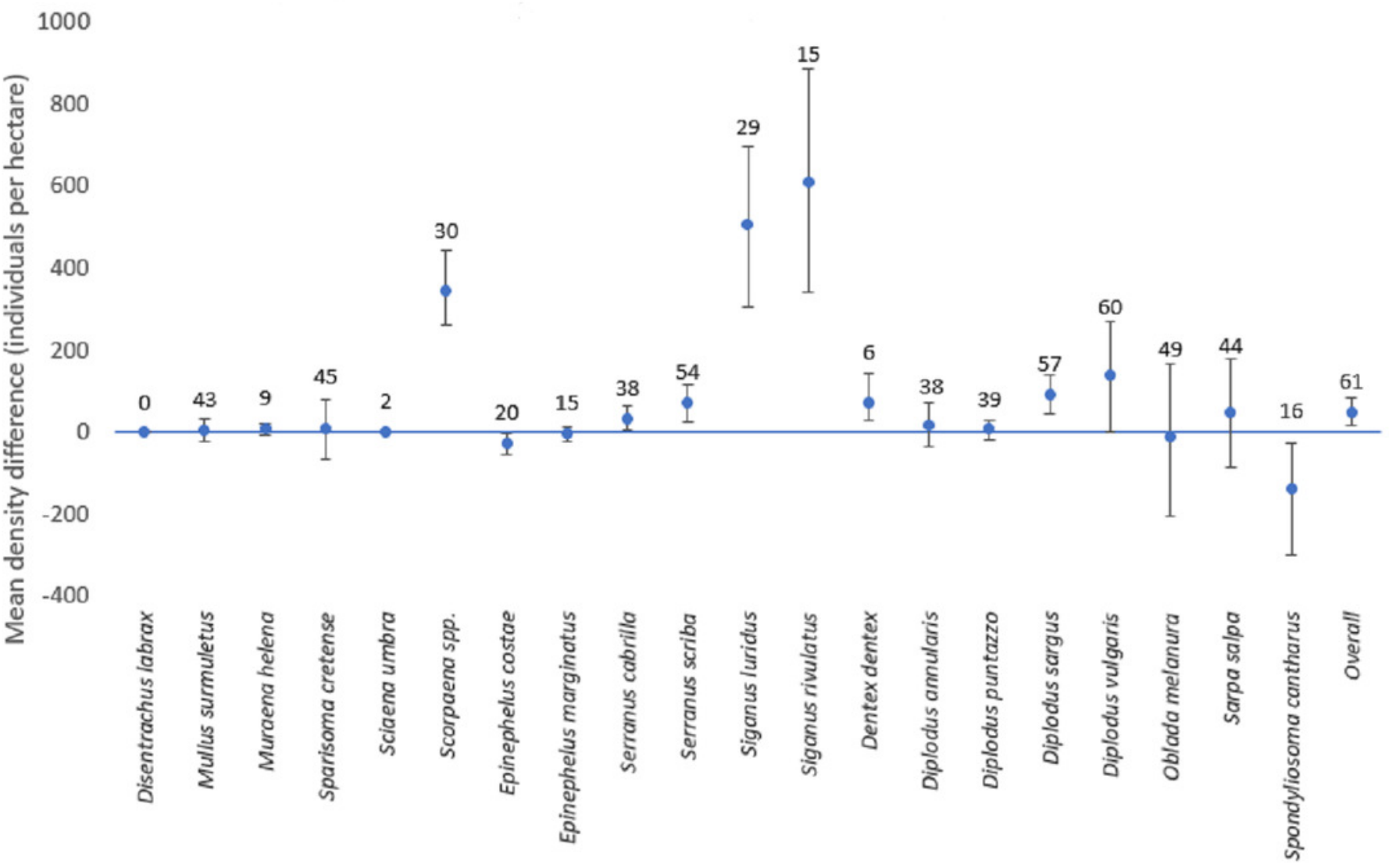




\section{Figure 6}

Two dimensional non metric multidimensional scaling ordination (MDS) for 31 paired-bymethod stations, based on square root-transformation density data and a Bray-Curtis similarity matrix.

Numbers correspond to the stations presented in Fig. 1. Paired-by-method stations with the highest similarities between the two methods are indicated by a circle, while those stations with the lowest similarities are joined with a straight line. North Aegean region stations (1-31 and 56-60) are marked in blue-green colors, while South Aegean stations (33-54) are depicted by red-orange colors.

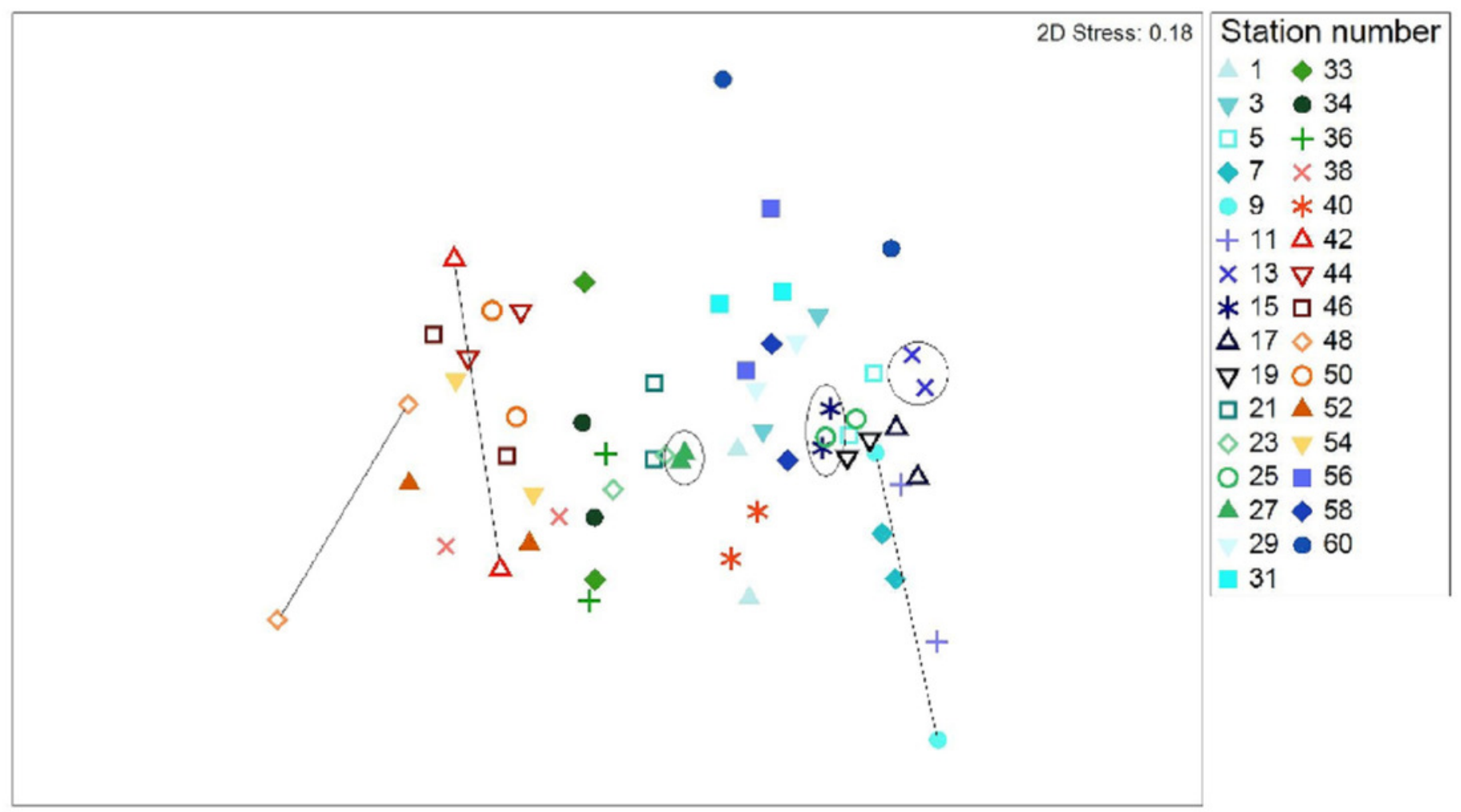




\section{Figure 7}

Cluster analysis of the paired-by-method stations' similarity, based on square roottransformation density data and a Bray-Curtis similarity matrix.

Numbers correspond to the stations presented in Fig.1. Paired-by-method stations with the highest similarities are indicated by a circle, while those with the lowest similarities are by arrows of different color. North Aegean region stations (1-31 and 56-60) are marked in bluegreen colors, while South Aegean stations (33-54) are depicted by red-orange colors).

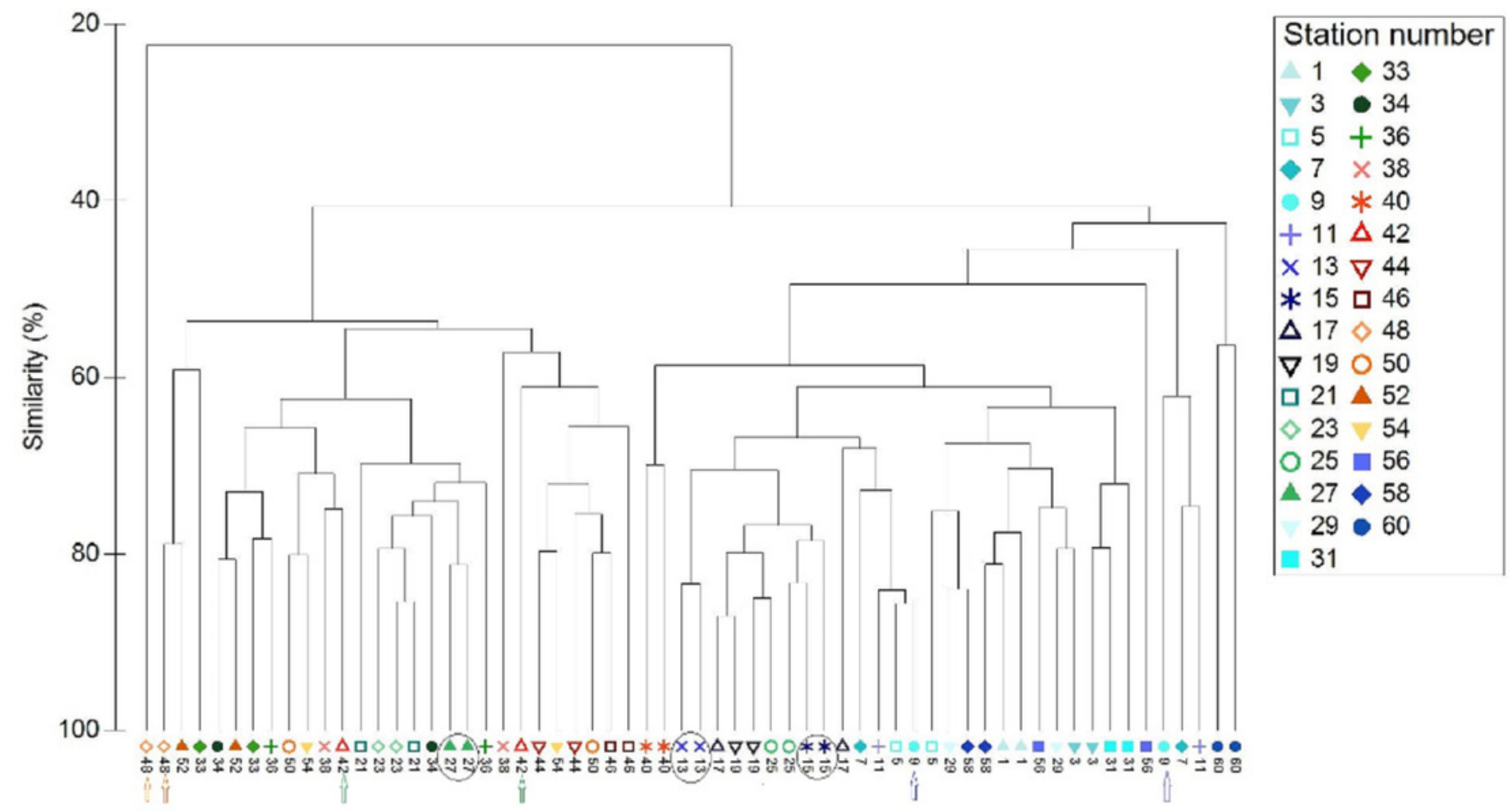

